\title{
Ideologia: O muro da escola
}

\section{Ideology: The obstacle to school}

\author{
Alessandra Adorni* \\ Leda Verdiani Tfouni** \\ Tatiana Cristina Ferreira**
}

\begin{abstract}
Resumo: O artigo mostra como o sujeito do discurso identifica-se com a ideologia dominante sem ter consciência disso. A reflexão pauta-se nos filmes "Pro dia nascer feliz" e "Entre les murs", a partir dos quais se intenta expor como a ideologia opera no discurso. Utilizamos os conceitos da Análise do Discurso (Pêcheux), sob a orientação de um paradigma não positivista, no qual os dados são entendidos como elementos indiciários de um modo de funcionamento discursivo. Nos dois filmes, é perceptível a diferença cultural e social entre os personagens, essa se materializa discursivamente e funciona como elemento de divisão, gerando a incompreensão e o atrito na relação professor-aluno-escola-pais. Consideramos o professor numa função de sujeito-colonizador, isto é, aquele que impõe sua cultura, seus conhecimentos e sua língua(gem) sobre os alunos, a fim de neutralizar as diferenças, produzindo o efeito de uma sociedade logicamente estabilizada, onde cada um ocuparia seu lugar "natural".
\end{abstract}

Palavras-chave: Ideologia. Discurso. Escola.

Abstract: The article shows how the subject of the discourse identifies with the dominant ideology without being aware of it. The reflection is based on the films "Pro dia nascer feliz" and "Entre les murs", with an attempt to demonstrate how ideology operates in speech. The concepts of discourse analysis by Pêcheux are used under the guidance of a positivist paradigm, in which data is understood as evidence elements of a discursive mode of operation. In both films, it can be observed the cultural and social difference among the characters; this difference materializes discursively and works as an element of division, generating the misunderstanding and friction in the teacher-pupil-school-parents relationship. The teacher is considered a subject with a colonizing role, i.e. one who imposes his/ her culture, knowledge and language on students in order to neutralize the differences producing the effect of a logically stabilized society, where everyone would have a 'natural' place.

Keywords: Ideology. Discourse. School.

\footnotetext{
*Mestranda em Psicologia na Universidade de São Paulo - USP.

${ }^{* *}$ Professora Doutora no Curso de Psicologia na Faculdade de Filosofia, Ciências e Letras. Universidade de São Paulo - USP.

*** Mestrado em Estudos da Linguagem na Universidade Estadual de Londrina - UEL. E-mail: tatyferreira@hotmail.com
} 
Muro que marca diversas e define limites Que mata o espaço onde a paz não existe Prende vidas, muda o alegre, cria o triste Muro calado machuca a terra, insiste (Jose Machado Verissimo, Muros e Rimas)

\section{Introdução}

Em meio a tanas falácias sobre a escola e seus coautores (pais, professores, diretores, alunos), interpelados por discursos dos quais cada um se acha dono, escolhemos dois filmes de grande repercussão no Brasil, que retratam tanto a escola brasileira como a estrangeira, tendo em vista a exploração televisiva sobre a identificação e relação entre "ensino e violência".

Assim, o artigo é composto, em sua parte inicial, pela análise do filme-documentário "Pro dia nascer feliz", dirigido por João Jardim, tendo como tema a educação e as desigualdades sociais. Contudo, o mesmo é definido por seu diretor como um diário de observações da vida do adolescente no Brasil em seis escolas, sendo uma privada e cinco públicas, de várias regiões do país. O filme revela as diversidades da desigual sociedade brasileira: na economia, na crença, na geografia, na cultura; realidades ainda não distantes da situação atual do ensino.

Como visão parcial e "mascarada" da escola estrangeira, compõe outra parte do artigo a abordagem do filme "Entre les murs", dirigido por Laurent Cantet, vencedor do Festival de Cannes em 2008, que mostra como é a relação entre professor e alunos numa sala de $7^{a}$ série; sendo que os alunos pertencem a diversas nacionalidades. A autenticidade desse filme se deve ao fato de François Bégaudeau ser o personagem-professor na ficção e na vida real; e também por ser o filme baseado no livro homônimo, que relata as experiências de Bégaudeau com seus alunos. Além disso, os alunos não são atores, e as cenas foram gravadas num colégio do leste de Paris.

A escolha dos filmes deve-se à proximidade entre as salas de aulas, isto é, nos dois filmes é perceptível a diferença cultural e social dos diferentes personagens, diferença que se materializa discursivamente e funciona como elemento de divisão, gerando a incompreensão e o atrito na relação professor-aluno-escola-pais. 
Consideramos que o professor funciona como um sujeito-colonizador, ou seja, aquele que tem por função impor sua cultura, seus conhecimentos e sua língua(gem) sobre os alunos, a fim de neutralizar as diferenças, produzindo o efeito de uma sociedade logicamente estabilizada, onde cada um ocuparia seu lugar "natural". Detentor do conhecimento legitimado como "certo", o mestre pode, deste modo, ser interpretado como uma espécie de mensageiro do "processo civilizatório". O discurso é visto, assim, como um grande campo de batalha, onde são instalados os vários tipos de violência.

Neste sentido, construiu-se um discurso científico estruturado ao redor do tema "escola", cujas condições de produção se localizam em uma análise da realidade educacional enquanto produto de uma ideologia que busca manter a desigualdade, fugindo das relações de identidade e subjetividade, ao mesmo tempo em que acena com a possibilidade de mudança e ascensão social através da escolarização, esta sendo vista como tradução do saber e do poder.

Um discurso materializado numa visão neocolonialista e imperial do mundo, conhecido como orientalismo, assim entendido:

O orientalismo expressa e representa essa parte, em termos culturais e mesmo ideológicos, num modo de discurso baseado em instituições, vocabulário, erudição, imagens, doutrinas, burocracias e estilos coloniais [...]. A relação entre Ocidente e o Oriente é uma relação de poder, de dominação, de graus variáveis de uma hegemonia complexa. (SAID, 1990, p.17).

O ensino é o reflexo do orientalismo por meio da relação professor e aluno, relação essa de proximidade, como um espelho refletindo sua própria imagem, como se essa pudesse se constituir de forma idêntica, sem sua subjetividade própria. Mas tal posição discursiva de "mestre do saber" coloca o professor, devido aos rituais coloniais (normas, horários, provas), como detentor do poder, o dominante, podendo exercer seu poder por meio de recompensa ou punição.

É esse processo colonizador que se faz presente e marcante na educação, por meio de um interdito, isto é, um conjunto de "já-ditos" que sustenta todo dizer. A colonização não foi aprendida, mas ela produziu e produz efeitos através da ideologia e do inconsciente. Ela só aparece de "roupagem nova", um novo sentido, 
não é qualquer um, pois, sendo produzido pela ideologia, ele tem a função de reequilibrar a ordem imaginária da sociedade, restabelecendo o mundo à sua estabilidade lógica. (TFOUNI, 2003, p.03)

\section{A Análise do Discurso pêcheutiana}

A Análise do Discurso (AD) proposta por Pêcheux possibilita uma investigação inovadora, pois apresenta "uma nova forma de reflexão sobre a linguagem que aceita o desconforto de não ajeitar nas evidências e no lugar já feito" (ORLANDI, 2002, p.7). Dentro da perspectiva da Análise do Discurso pêcheutiana, a linguagem está materializada na ideologia assim como esta se manifesta na linguagem. Concebemos, também, o discurso, enquanto efeito de sentidos, como um lugar particular em que esta relação ocorre.

Para entendermos os aportes teóricos da Análise do Discurso, faz-se necessário chamar a atenção para a leitura que Pêcheux fez de textos da Althusser, ou seja, o momento que passa a pensar nas relações entre discurso e ideologia. Nesse momento, o autor parte do conceito de materialismo histórico dado por Althusser para mostrar o importante papel que a ideologia representa no processo de interdição dos sentidos. E, deste modo, propõe o conceito de "condições de produção": mostra que o discurso é efeito de sentidos entre os interlocutores.

Temos assim que o indivíduo não está livre para escolher de forma deliberada, numa determinada situação, o que falar, pois o seu dizer estará sendo afetado por este "já-lá", que Pêcheux denomina de interdiscurso ou "o todo complexo com dominante das formações discursivas" (1988, p.162). Esse "já-lá" dia respeito a sentidos que foram se construindo historicamente a partir das inúmeras relações de poder, que podem ou não ser assumidos pelo sujeito, a depender das posições discursivas que este poderá ou não ocupar de acordo com o funcionamento da ideologia.

AAD entende o funcionamento da ideologia, em sua imbricação com o discurso, como direcionamento do sentido determinado por dadas condições de produção históricas. A ideologia, então, "não se define como o conjunto de representações, nem muito menos como ocultação de realidade. Ela é efeito da relação do sujeito com a língua e com a história em sua relação necessária, para que se signifique" (ORLANDI, 1998, p. 48). 
A produção de sentido deve-se a um entrelaçamento efeito-sujeito à linguagem numa dada formação discursiva, ideológica, inconsciente. Por meio dele:

todo e qualquer dizer tem um caráter inescapavelmente histórico, ou seja, é impossível pensar na linguagem, no sujeito e no sentido fora dessa relação, que caracterizaremos como visceral: condição necessária de constituição e de funcionamento de todo discurso. É isto que confere ao acontecimento de linguagem um caráter repetível, especialmente por sua relação com uma (ou mais) formação discursiva: os dizeres possíveis em determinado momento sócio-histórico. O acontecimento da ordem do repetível, ao entrar em contato com o novo, específico de um dado tempo, reatualiza a enunciação, o que pode levar à emergência de um novo sentido em um enunciado, ou, ainda, a um novo enunciado. (TFOUNI, 2008, p.149).

Pêcheux (1988) ainda diz que esse novo enunciado sempre pode vir a ser outro, por meio de deslocamentos de sentidos causados pelo próprio funcionamento do discurso. É nesses deslocamentos que o analista se estranha para tentar buscar como agiram os esquecimentos número 1, de que o sujeito é origem de seu dizer, e o número 2 , de que o que diz corresponde literalmente ao que pensa.

AD não considera a linguagem como uma transparência, ou imanência, de onde se poderia apreender um sentido "pronto e completo", anterior ao texto e à sua produção. A linguagem é opaca, e o que a AD se propõe a fazer é mostrar esta opacidade, "desautomizar os sentidos [...] analisando-se, por exemplo, o efeito do já-lá, e o pré-construído" do discurso, como proposto por Tfouni (2003, p.18).

Neste sentido, o sujeito passa a ser uma posição (inconsciente) assumida diante da ideologia. Para a $\mathrm{AD}$, o sujeito não tem controle sobre o que fala, uma vez que ele é afetado tanto pela ideologia quanto pelo inconsciente. Deste modo, pode o sujeito, por meio de seu discurso, evidenciar uma identificação com a ideologia dominante, mesmo não pertencendo a essa classe e sem ter consciência disso. Tentaremos mostrar a seguir, por meio da análise dos dois filmes, como os sujeitos são interpelados pela ideologia. 


\subsection{A metodologia indiciária}

A A.D., como dispositivo de análise, pressupõe que os dados não são vistos de forma automática, como decodificação, mas algo a ser interpretado, no sentido de desvendar a historicidade contida na linguagem e em seus mecanismos imaginários. Os dados são entendidos, conforme propõe Tfouni (1992, p. 206), "[...] como elementos indiciários de um modo de funcionamento discursivo".

Nesta perspectiva, consideramos que a linguagem despe-se de sua materialidade, exclui-se o contexto sócio-histórico de produção de sentidos e, ao mesmo tempo, o processo no qual se constitui o sujeito que enuncia. Segundo Orlandi (1996, p. 23), "se as ciências se constituem pressupondo uma certa noção de linguagem e sujeito, é na transformação dessas noções que também está o deslocamento de seus (delas) limites e, consequentemente, de suas relações".

Assinalamos ainda que a AD considera a língua em si mesma, tratando-a em sua inscrição na história, fundando assim seu objeto novo: o discurso. Sabendo-se ainda que:

todo discurso se estabelece sobre um discurso anterior, apontando para outro [...]. O que existe não é um discurso fechado em si, mas um processo discursivo, do qual se podem recortar e analisar estados diferentes. (ORLANDI, 1996, p. 56).

Se a AD lida com as marcas, os indícios linguísticos que ancoram o sentido evidente do texto a um exterior, a uma memória discursiva que o faz significar e que, por sua vez, está intrincada na constituição do sujeito que enuncia, então, dentro da noção de contextualização da investigação, o investigador tem que se deslocar da posição central de controlador para controlar-se como: "um produto sócio-histórico que está analisando outros produtos sócio-históricos. Tudo isso sem perder de vista os processos que geraram esses produtos". (TFOUNI, 1992, p. 214)

\subsection{0 muro}

$\mathrm{O}$ artigo propõe uma reflexão sob um muro antigo (saber x poder), o qual diferencia, separa os que sabem (têm o poder) dos que não sabem 
(dominados). Nesta perspectiva, a educação cria os meios para a prática do poder, isto é, aqueles que possuem o controle dos processos educacionais não permitem o questionamento da ideologia burguesa, impedem a possibilidade de outros manipularem os mesmos instrumentos para o que eles devem saber e o que podem saber.

Desta forma, a educação além de produzir o que os donos do saber julgam importante para a classe trabalhadora saber, produz também o que não saber, o que ignorar. Assim, a educação é orientada por uma ideologia que não permite de todo a democratização de possibilidade para a compreensão e questionamento da vida social e política, como proposto nos Parâmetros Curriculares Nacionais (PCNs).

A educação está a serviço do comando de uma ideologia que controla o todo da vida social e que articula a exaltação da diferenciação e legitimação, sob a égide da democratização. Uma classe possui uma educação diferente da outra, o que é justificado pelo nome da democracia. E é nessa pirâmide que encontramos um rosto que assume a cara de todo esse processo: o professor.

O professor, na posição discursiva de sujeito-colonizador, assume frente ao seu aluno e ao conhecimento a posição daquele que detém todo o saber e o poder sobre o que fala; no entanto, devido à presença de diferentes posições, bem como a presença de interesses distintos frente aos diferentes momentos históricos, notamos a presença de múltiplas posições do sujeito frente à ideologia. Sabendo-se que a ideologia não afeta a todos os sujeitos da mesma maneira, é possível perceber que os discursos ora resistem, ora se contradizem, ora se subordinam, revelando, por meio da análise, indícios sobre o posicionamento ideológico daqueles vivem ou participam da vida escolar.

Antes de partirmos para a análise do filme "Pro dia nascer feliz", deixamos claro que as falas aparecerão como por nós foi ouvida, mas dentro do padrão da língua portuguesa e, também, em alguns momentos, não colocaremos os nomes dos alunos e sim a categoria “aluno". No entanto, como explicitação do dito, poderá aparecer o nome da personagem. O intuito é analisar os recortes de uma dada classe, num determinado contexto sócio-cultural-histórico.

No exemplo a seguir, é possível ver as marcas de expectativa dos pais sobre seus filhos com relação à educação: 
"Eu queria um futuro para ela que eu não tive oportunidade... de estudo." (fala de uma mãe de aluna de escola pública)

Neste trecho nota-se como a mãe coloca uma expectativa perdida num primeiro momento, porém com uma nova oportunidade de ser realizada pela filha, num segundo momento. Vemos o quanto a escola possibilita ao sujeito o sentimento de identidade, pertença e inserção social, ou seja, um lugar no mundo. A ilusão do saber como poder, redenção, status.

Isso fica claro, ainda, em uma das falas de uma aluna de escola pública que não via sentido na vida senão a morte até ser incentivada pela professora a participar de um projeto de poesia: " "eu só dormia... seria a solução para os meus problemas, o mais fácil"; ou na fala de uma aluna de escola particular, quando descobre que o pai teve um momento na vida em que não era cristão, porém ela estudava num dos melhores colégios católicos, assim entrou em crise: 3 "faço parte desse mundo atual em que vivo ou tudo é mentira". Momentos em que o espelho pai ou professor fazem parte da construção desse sujeito, e quando ele não se vê nele refletido, ele se desestrutura.

No entanto, há também uma expectativa do professor com relação ao aluno e os coparticipantes da escola, pois este sujeito também possui uma história e uma posição ideológica frente ao outro. Esse sujeito é constituído subjetivamente de seus processos inconscientes e de suas (im)possibilidades de manejar seus limites.

Note-se isso num depoimento de uma professora de escola pública que diz: "Vivi a vida da minha mãe". Desse lugar, tal professora tenta encontrar alunos coparceiros dessa posição para tentar mostrar sua frustração: ser como ela foi não vai ajudar. Viver a vida dos pais tem um custo (frustração), perde-se um tempo sem viver a sua própria vida. Ou o caso de outra professora, que se deixa envolver com histórias entre os pais e os seus alunos: "É muito psicológico, eu faço terapia". Assim, tem-se sujeitos constituídos de história e afetados por uma ideologia que os levará a um campo de batalha, onde cada um tenta ocupar ou marcar um espaço.

\footnotetext{
${ }^{1}$ Duque de Caxias, Rio de Janeiro.

${ }^{2}$ Keila, 16 anos.

${ }^{3}$ Thaís, 15 anos. Colégio Santa Cruz.

${ }^{4}$ Professora Edilaine, Núcleo de Cultura da Escola do Rio de Janeiro.
} 
No recorte a seguir, o sujeito brinca com as posições "ela, ele e eu", pois são os sujeitos que emergem em papéis sócio-históricos, inseridos numa determinada ideologia, além de o mesmo sujeito intensificar a negação verbal: "não acredito mais; não cumpri mais"; com consequências ideológicas relacionadas à descaracterização da escola e do processo educacional. Usa ainda uma afirmativa seguida de uma negativa: "está preparado/ não está preparado", aparecendo a censura consciente, relacionada a sua posição de sujeito ocupada nesse momento (diretora/professora).

"Eu não acredito mais na educação, ela não cumpre mais a sua função... o professor está preparado, ele não está preparado para esse tipo de humano." (atualmente diretora, mas também é professora)

E, ainda, o dito: "esse tipo de humano" vem naturalizado de discursos anteriores, como: "preocupa-se o país com o problema da juventude transviada: - alguém lhe deu uma escola?... alguém lhe deu uma oportunidade?” Traça-se, assim, um sujeito sempre fora das normas, e com quem ninguém sabe lidar, surge como um saber oficial que produz efeito de transparência de sentido e de verdade. Por meio desse discurso o sujeito interioriza as normas e essas proporcionam uma identificação com uma determinada formação ideológica dominante (“somos rebeldes, sim!; não queremos nada, mesmo!...”).

"Nosso colégio não presta..."

"Eles vêm para extravasar."

"A professora ensina errado..."

"Eles ensinam, muitos alunos é que não prestam atenção."

“Até os desistentes tiram a mesma nota porque ela não ia dar aula."

Os enunciadores desse dizer são, na verdade, o próprio objeto do dizer, ou seja, os sujeitos-alunos que colocam a escola como um lugar desigual e ruim, ou por causa deles ou pelos professores, e iludem-se, pois desta forma identificam-se com a posição do outro. Ao dizer sentem-se donos do que dizem, um lugar onde as diferenças e desigualdades são apagadas, pois todos diriam igual nessas mesmas condições, há um laço que os amarra ao dito que dizem e desejam criticar.

${ }^{5}$ Aluna Clésia, 13 anos. Pernambuco. 
Nesse sentido, os filmes nos trazem recortes de uma colonização que ainda vige sobre nós e principalmente na educação. O sistema trazido pelo colonizador continua em nós, em nossas práticas didáticas, por isso os conflitos no discurso, como diz, sabiamente, a ${ }^{6}$ Prof. ${ }^{a}$ Celsa: "Ninguém entende ninguém... O Estado deixa tudo jogado... maquia-se muito as coisas...” E, como consequência do não entendimento, a reação é a violência em suas várias faces.

Nesse dito da Prof. ${ }^{a}$ Celsa, notamos uma visão negativa da escola e também uma crítica, pois assim não há culpados e nem pessoas que farão a diferença dentro do ambiente escolar. Ainda é possível perceber certa resistência ao dito, ou seja, uma leitura alternativa. Isso ocorre porque as posições-sujeito podem ser ocupadas, e tanto num caso quanto no outro, são imprevisíveis. Independe de classe social, profissional, pois a ideologia interpela o indivíduo em sujeito de maneira inconsciente, e, portanto, mesmo carregado da melhor das intenções, o sujeito do discurso, ainda que sem se dar conta, pode adotar um discurso difamatório ou negativo, inclusive sobre si mesmo.

Ainda no dito da diretora de escola pública: “[...] eu não acredito mais na educação...", a sua falta de crença em seu próprio trabalho e na sua adaptação a situações novas torna mais fácil a não tomada de posição, ou seja, abster-se de sua função é mais fácil, até porque "toda culpa é do Estado". Achar o culpado (o colonizador) é mais fácil do que sair dos laços de colonizado.

Parece haver uma predominância entre o uso de algumas formas linguísticas que estariam a favor da manutenção das formações ideológicas dominantes e de outros lugares, nos quais é possível enxergar pontos de deslizes e, ao mesmo tempo, de resistência a essas formações. Essa polarização aparece de maneira privilegiada relativamente à questão econômica, como se pode observar nestas expressões de alunos:

"A gente continua na bolha"

"Ajudar alguém supõe superioridade"

"Nós somos a sociedade da minoria"

As palavras "bolha", "superioridade" e "minoria" estão deslocadas, já que aparecem nas suas diferentes combinações, com outros elementos linguísticos, produzindo um efeito de sentido que revela uma formação ideológica

\footnotetext{
${ }^{6}$ Professora da Escola Parque Piratininga II, Itaquacetuba-SP.
} 
dominante, em que os ricos estão sempre protegidos por uma bolha ou ficam na bolha para não ter contato com o resto (pobres), a minoria, os inferiores. A bolha também vem com o significado da indiferença, da anulação, do "fechar os olhos" ao que está à frente.

Há ainda uma ideia de que fazer parte da minoria significa acomodar-se à situação por acreditar que não possa mudá-la ou sair da condição de dominado. A palavra "minoria" carrega a memória semântica do sentido das palavras "colonizado", "inferior".

"Hoje vamos aprender o imperfeito do subjuntivo". Prof. Bégaudeau "Não precisamos aprender isso [...], não usamos, não falamos [...]." Aluna

No trecho citado, do filme "Entre les murs", há uma presença marcante, nos longos diálogos, da imposição da língua francesa para um público com diferentes culturas e idiomas. O próprio título refere-se aos muros, barreiras que separaram e separam os diferentes idiomas. Assim, a formação ideológica do colonizador-colonizado fica evidente: neste trecho do filme há uma tentativa de imposição da língua e aqueles que são "rebeldes" (rebelam-se contra as normas) sofrem penalidades como suspensão e expulsão da escola.

Há apenas um caso dentre os outros alunos da escola que é tido como "exemplo": o do aluno Wei (chinês). O Estado (França) decretara a sua deportação e de sua família, e devido a este fato os professores realizam um conselho para ver o que podiam fazer, já que se tratava de seu melhor aluno. Isso ocorre porque Wei era tido como aluno modelo (aprendia bem o francês e seguia as normas), e era um bom aluno (comportamento). Legítimo exemplo de como ocorre a imposição e o modelo de espelho a ser seguido pelos colegas.

Nas escolas particulares do Brasil também ocorre a exposição dos melhores, os que "aceitam a querer saber mais"; esse é o aluno disputado pelas escolas, escolhido para propagandas de cursinho e cerimônias de entregas de troféu. Um exemplo a ser citado é o caso de uma aluna que declara, naquele ano, ter esquecido um pouco de seu lado juvenil e feminino devido ao excesso de atividades cumpridas na escola e fora desta. E ainda passava pela disputa de outros colégios que a queriam para si, pois houvera ganhado olimpíadas naquele ano.

${ }^{7}$ Ciça, 16 anos. Colégio Santa Cruz. Bairro Alto de Pinheiros-SP. 
Essa transposição de um "já-dito", que se encontra nas formações ideológicas dominantes, e que apresenta uma explicação a respeito de quem tem mais, de quem é superior, de quem pode ajudar e de quem não pode, pode ser explicada por uma interpelação ideológica que faz com que o sujeito desse dizer se identifique com essas formações ideológicas discursivas e não com outras.

\section{Considerações finais}

Ao realizar a análise percebemos o quanto ela contribui para mostrar que a ideologia não é consciente, "ela é efeito da relação do sujeito com a língua e com a história em sua relação necessária, para que signifique". (Orlandi, 1996, p. 48) A relação com a ideologia e a constituição de sentidos não ocorre de forma estática e nem automática, é preciso analisar o discurso a partir do seu funcionamento.

Num todo, temos a escola como um enunciador que silencia: os aspectos históricos do sistema educacional - como surgiu e se desenvolveu no Brasil e no mundo; as múltiplas funções da educação para a construção do indivíduo e suas relações sociais e o papel de outras instituições na formação do sujeito, como a família e a comunidade.

Assim, as palavras e expressões ditas são marcadas por enunciadores do dizer, estes são o próprio objeto do dizer, isto é, são sujeitos, na posição de professor, alunos, pais que estão a favor da manutenção das formações ideológicas dominantes, e em outros lugares, nos dois filmes, onde é possível enxergar pontos de deriva e ao mesmo tempo de resistência a essas formações.

\section{Referências}

ORLANDI, E. Nota ao leitor. In: PÊCHEUX, M. O discurso: estrutura ou acontecimento. Campinas: Pontes, 2002.

Janeiro: Vozes, 1998.

Interpretação: autoria, leitura e efeitos do trabalho simbólico. Petrópolis, Rio de

Interpretação e autoria: leitura e efeitos do trabalho simbólico. Rio de Janeiro: Vozes, 1996.

PÊCHEUX, M. Semântica e discurso: uma crítica à afirmação do óbvio. São Paulo: Editora da UNICAMP, 1988. 
SAID, Edward W. Orientalismo: o Oriente como invenção do Ocidente. Trad. Tomás Rosa Bueno. São Paulo: Companhia das Letras, 1990.

TFOUNI, F. E. V. A linguagem e o sintoma na análise de "slogans": a fetichização da mercadoria. Tese (Doutorado em Linguística) - Universidade Estadual Paulista, Araraquara, 2003.

TFOUNI, L. V. O dado como indício e a contextualização do(a) pesquisador(a) nos estudos sobre a compreensão da linguagem. Delta, v. 8, n. 2, p. 205-253, 1992.

O autor como intérprete - as fronteiras entre a Análise do Discurso e a Psicanálise lacaniana. IN: Congresso Internacional da ABRALIN, 5. Anais..., Belo Horizonte, p.0106. 2007.

. Múltiplas faces da autoria. In: TFOUNI, L.V. (Org.). Autoria e contenção da deriva. Ijuí: Ed. Unijuí, p.141-158, 2008.

Recebido para publicação em 8 nov. 2010. Aceito para publicação em 20 dez. 2010. 